Egypt. Acad. J. biolog. Sci., 1(2): 205 - 210 (2008)

E. mail. egyptianacademic@yahoo.com

ISSN: $1687-8809$

Received: $2 / 12 / 2008$

\title{
Some inorganic salts for production of sterile adults of the red palm weevil Rhynchophorus ferruginous (Coleoptera:Curculionidae)
}

\author{
Sharaby. A. ; EL-Hawari F. M. and Ibrahim, S. A. \\ Pests and Plant Protection Dept. Naional Research Center, Cairo ,Egypt.
}

\begin{abstract}
Fifteen inorganic salts were evaluated as possible sterilants against the Red Palm Weevil (RPW) Rhynchophprus ferrugineus, by applying the pupal dipping method in a screening program. Results showed that all tested salts adversely affected the adult emergence and reduced the egg laying capacity and egg hatchability. Among the tested salts a $(\mathrm{oH})_{2}, \mathrm{kOH}, \mathrm{Licl}_{2}, \mathrm{cucl}_{2} \mathrm{ZnO}_{4}, \mathrm{kBr}$ and $\mathrm{KI}$ various gave $100 \%$ percent sterility at the tested non toxic concentration under different pupal dipping periods. Percentage of sterility increased with the increase of the concentration and the dipping period. All other salts induced degrees of sterility ranging from 10 to $78 \%$.
\end{abstract}

Key words: Rhynchophorous ferruginous, chemosterilants, inorganic salts

\section{INTRODUCTION}

The red palm weevil Rhynchophorous ferruginous is the most important insect pest for the date palm trees in the middle east and Gulf states. The insect could be distributed through most of the Arab world that cultivated the date palm trees by transferring the infested shoots from place to another. The larvae of the insect feed inside the tree trunk making dangerous tunnels and led to dumping off the tree The new trend of pest control is searching for safe and available alternative materials of dangerous insecticides. Many attempts have been made to chemo sterilize the insects in adult stages, less effort has been made on treatment of the pupal stages. Pandery and Teotia (1980) tested 18 alkylating compounds, 10 antimetabolites and 8 compounds belonging to miscellaneous groups by pupal dipping methods, they found that the promising chemosterilants for Sitotroga cerealella (Oliver) are to be found among the aziridines especially Tepa, Metepa, Thiotepa and ENT50761 at low concentrations causing high sterility. Neerja and Upadhyay(1985)recorded that sterility can be induced in adults of rice moth Corcyra cephalonica (Stant) following pupal dipping methods in different amino acids: Ornithin, $\dot{\alpha}$-Glutamine, Valine, Serine and Alanine. Sharaby (1987) found that twenty four inorganic salts evaluated as sterilants for the lesser cotton leaf worm Spodoptera exigua (Hubn.), by applying the pupal dipping techniques in a screening program. A Compendium of inorganic substances used in European pest control before 1850 were recorded by Smith and Secoy (1976); a list of 24 inorganic chemicals used in European agriculture up to 1850 for pest control is given ,together with description of their recorded. Attempts have been made to assess their possible efficacy. In the present study some inorganic salts were tested for the first time for their efficacy by pupal dipping techniques with a view to evaluate the promising and effective chemosterilants against the RPW $R$. ferruginous as a new approach in its control programes. 


\section{MATERIAL AND METHODS}

Tested insects were obtained from infested palm trees then maintained under laboratory culture on bulb of date palm tree (main host) (EL-Dosary;2006) at $28 \pm 2 \mathrm{c}^{\circ}$ where its life cycle not exceeding 55-60 day and the time for pupation from egg lying was 30days. Pupae with its cocoon were collected for the experimental tests. Three different serial concentrations 5,10and $15 \%$ of fifteen inorganic salts were prepared by dissolving in distilled water. Pupae, about 2-4days old were selected from the culture for dipping treatment. The pupae were placed in a small wire basket $(10 \times 20 \mathrm{~cm}$. $)$ and immersed inside a beaker $(500 \mathrm{ml}$.) containing the tested salt solution. The experiments were carried out by taking two different dipping periods 20and 30 min. Treated pupae were washed with water and left to dry, then introduced into a glass jars ,left till adult emergence. Both sexes of pupae were accordingly treated with the same treatment, while the control was treated with distilled water and run side by side. Five pupae were used for each test, all tests were repeated three times. Observations on the percentage of adults emergence from pupae were recorded both from treated and untreated individuals. To evaluate the fecundity of adults and egg hatchability, pairs of one male with one female of normal adults emerged out of treated pupae were confined in a glass egg laying jars $(1$ Liter $)$ containing piece of date palm tree bulb as a site for egg laying. Deposited eggs were collected every two days and counted. Data were subjected to analysis of variance and Duncan's multiple range test (1965) for determining their significance. Sterilizing percentages were calculated by the formula described by Crystal (1968) as follows.

$\%$ Sterilization is defined as $100(1-\mathrm{fh})$, where $\mathrm{f}$ and $\mathrm{h}$ are the corrected decimal fractions of percentages of fecundity and fertility hatchability, respectively.

The tested inorganic salts:

Hydroxides: $\mathrm{NaOH}, \mathrm{KOH}, \mathrm{Ca}(\mathrm{OH})_{2}$.

Chlorides: $\mathrm{Licl}, \mathrm{Nacl}, \mathrm{Mgcl}_{2}, \mathrm{Cucl}_{2}$.

Nitrate: $\mathrm{NaNO}_{3}$

Acetate: $\mathrm{CH}_{2} \mathrm{COOLi}$

Sulphate: $\mathrm{Na}_{2} \mathrm{So}_{4}, \mathrm{Mg} \mathrm{So} 4, \mathrm{ZnSo}_{4}$

Bromide: $\mathrm{KBr}$

Iodide: $\mathrm{KI}$

Phosphate: $\mathrm{Na}_{2} \mathrm{HpO}_{4}$.

\section{RESULTS AND DISSCUTION}

Results for screening the 15 inorganic salts at various concentrations and dipping periods are given in Table (1). It is apparent from the results that six salts gave the best results where they gave $100 \%$ sterility at the different tested concentrations and the dipping intervals 15 and $30 \mathrm{~min}$. The six salts were as follows: Hydroxides: $\mathrm{Ca}(\mathrm{OH})_{2}$, Chlorides: Licl and $\mathrm{cucl}_{2}$, Sulphate: $\mathrm{ZnSO}_{4}$, Bromide: $\mathrm{KBr}$ and Iodide: KI However, all tested salts adversely affected the adult emergence and reduced the egg laying capacity and egg hatchability comparing with the control test . The sterility produced was of a high level for most of the tested salts, percentages of fecundity and hatchability were significantly reduced by increasing the salt concentration and the time interval of pupal dipping. Shraby(1987) recorded that some inorganic salts had a promising effect as chrmosterilants against S.exigua by appling the pupal dipping method in a screening program. Among the tested salts, $\mathrm{Ca}(\mathrm{OH})_{2}, \mathrm{NaOH}_{2}, \mathrm{LiCl}_{2}, \mathrm{CuCl}_{2}, \mathrm{NHCl}_{2}, \mathrm{CH}_{2} \mathrm{COOLi}, \mathrm{ZnSO}_{4}, \mathrm{KBr}$ and $\mathrm{KI}$ gave $100 \%$ 
sterility at the tested non toxic concentration under different pupal dipping periods, another salts induced various degrees of sterility ranging from $31-97 \%$. Soluble inorganic salts are transported across cell membranes (Frings, 1946 and Dethier, 1955) and it was suggested that the penetration of the salts through the cell membrane is according to the order of ionic mobility which will determine the order of effectiveness. Effect of the tested salts might be a result of accumulation of salt ions in the tissues of the pupae after treatment and their interference with the biological processes of the pupae, causing retardation in development of the reproductive system. It might be also of some adverse effect on the viability of sperms and ovaries in either sex of $R$. ferruginous adults. Gehad et al. (2007) recorded the toxic effect of four inorganic groups (Copper sulfate, Copper hydroxide, Copper oxychloride) was great toxicity on some piercing sucking insects (Aphids, Aphis gossypii., white fly, Bemisia tabaci., Gassyd, E. lybica.,and Mites,Tetranycus urtica) that infested the small seedlings of cucumber plants. The tested materials has a great toxicity as acaricidal and insecticidal agents for controlling the pests without any harmful effect on the treated plant. Salama and Sharaby (1973) discussed the effect of $\mathrm{ZnSO}_{4}$ on the feeding and growth of Spodoptera littoralis and they found accumulation of Zink in tissue of the larvae seems to be the factor inducing moths sterility. Flint et al. (1968a,b) conducted the screening test with several compounds including aziridines, methanesulphnates, nitrogen mustards, phosphor amides and urea derivatives by topical application or feeding to adult Heliothis virescens. They showed that azirdines were the only promising chemostarilant to the Lepidopteras isects. Campion (1967) indicated that only Tepa, Metepa and Apholate caused complete srerility to male red bollworm Dispropsis castanea, while no sterility was induced by using Hempa . The present results cleared that the solution of the tested inorganic salts could be used as a chemosterilent for $R$. ferrugineus by injection in the infested tree trunk or roots as alternatives to the harmful chemical insecticides, or as a new approach to its control for mass production of this pest by sterile techniques. 
Table 1: Effect of pupal dipping of Rhynchoporus ferrugineus in different concentrations of inorganic salts for different periods on the adults sterility.

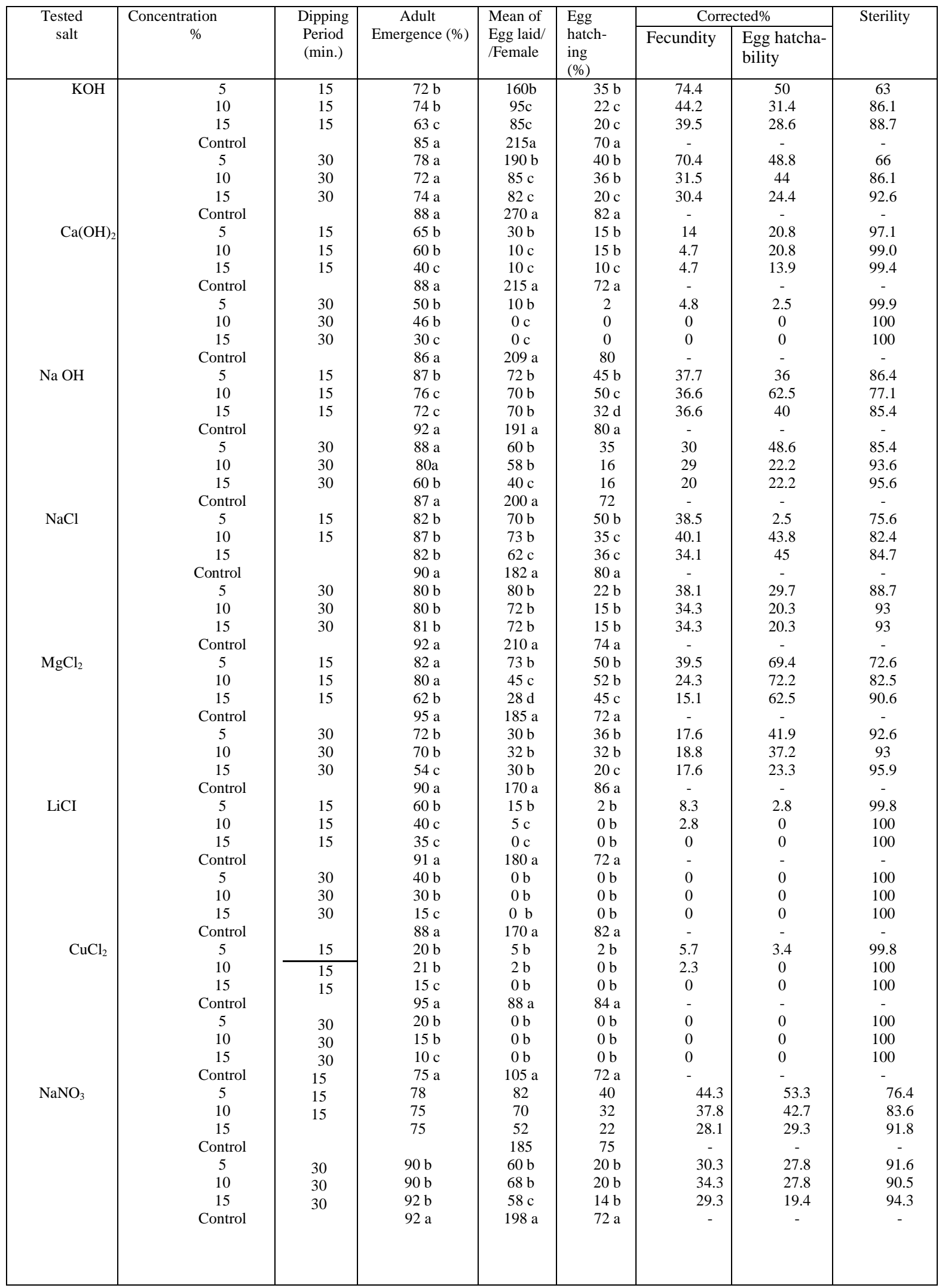




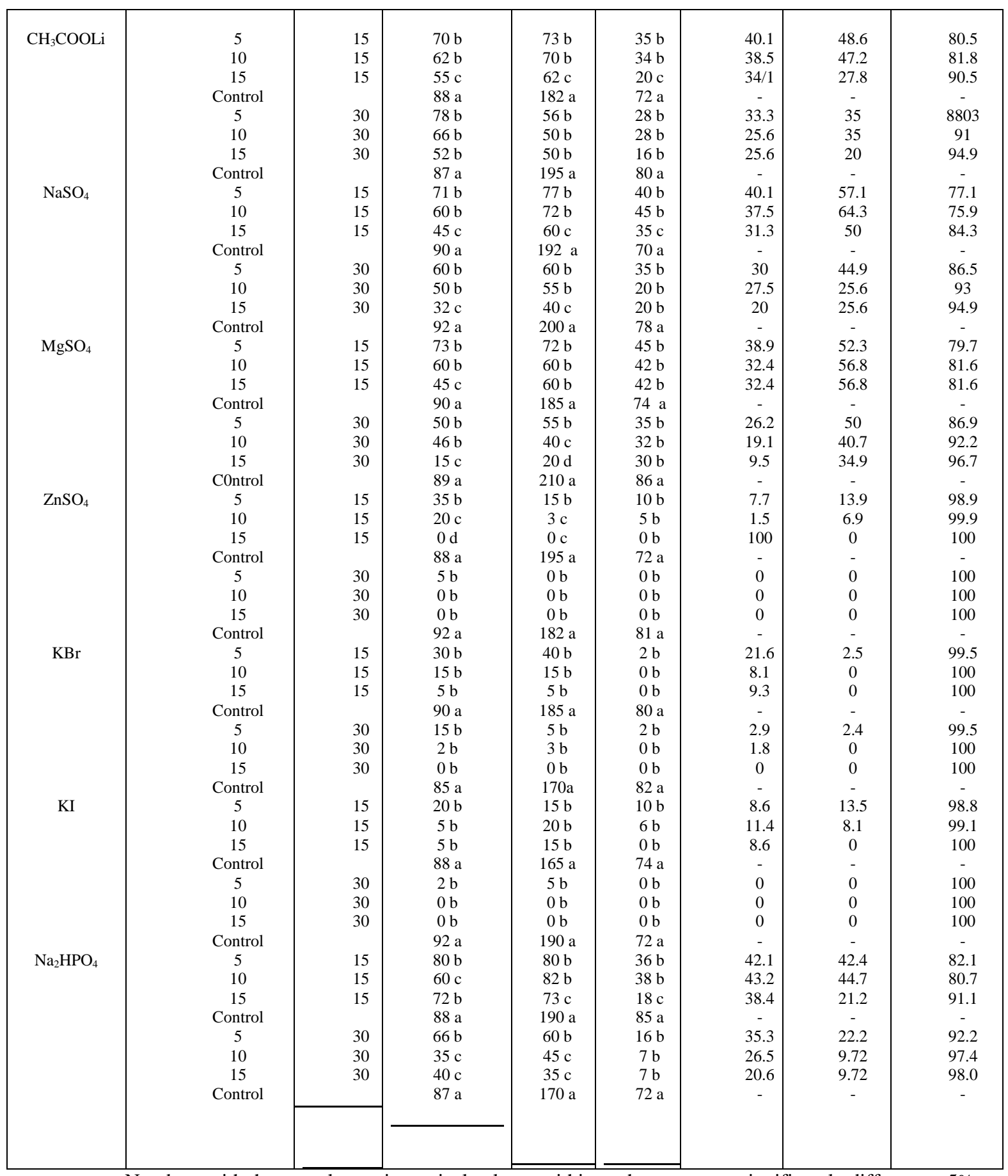

Numbers with the same letters in vertical column within each test are not significantly different at $5 \%$ level $(\mathrm{P}=0.05)$. Duncan's multiple range test (1965).

\section{REFERENCES}

Al-Dosary, M. (2006). Sensory receptors and behavior of the red palm weevil Rhynchophprus ferrugineus (Oliv.) (Coleoptera:Curculionidae) with reference to attractants, repellents and control. Ph.D.Thesis in Science/Zoology Arthropods and Parasites(Entomology) Biology Department, Girls College of Education Scientific Divisions in Al-Kharj Riyadh, K. S. A. 
Crystal, M. M. (1968). Sexual sterilization of screw worm by N. N: Tetramethylene bis (I-aziridure) carboxamide: Influence of route of administration. J. Econ. Ent., 61(1):134-139.

Dethiert,V.G.(1955).The physiology and histology of the contact chemo receptors of the blowfly. Quart. Rev. Biol. 30:348-31.

Duncan,D.B.(1965):Multiple range and multiple F-test.Biometrics,11:1-41.

Frings, H. (1946).Gustatory thresholds for sucrose and electrolytes for the cockroach, Periplanata americana (Linn.). J. Exp Zool.102:23-50.

Flint, H. M., Kalssen, W.; Norland, J. F.; Kressin, E. L. (1968): Chemosterilization of tobacco budworm,A survey of 16 compounds fed to adult moth. J. Econ Ent., 61(6)1726-1729.

Gehad, M. M.; Al-Saqabi, S. M.; El-Sisi, A. G. (2007). Acaricidal and insecticidal efficacy of some recommended cupreous fungicides against suking piercing pests. The Second International Conference of Economic Entomology, 8-11 Dec., Cairo, Egypt. pp96.

Neerja, A.and Upadhyay, K. D. (1985). Screening of certain amino acids as possible sterilants against rice moth Corcyra cephalonica (Staint). Bull. Grain. Technol. 20(1):37-42.

Pandey, G. P.and Teotia,T. P. S. (1980). Laboratory studies on chemosterilization of angoumois grain moth Sitotroga cerealella (Oliv) Screening of 33 compounds by pupal treatments. Indian. J. Ent. 42(1):1-15.

Salama,H.S. and Sharaby, A. (1973). Effect of Zinc sulphate on the feeding and growth of Spodoptera littoralis (Boisd.). Z. ang.Ent.72:383-389.

Sharaby,A.(1987). Screening of certain inorganic salts as possible sterilants against the lesser cotton leafworm Spodoptera exigua (HBN), by pupal reatments.Bull.ent.Soc.Egypt.Eco.Ser.,16.269-282.

Smith. A. E. and Secoy. D. M.(1976). A Compendium of inorganic substances used in European pest control before 1850. J. Agric. Food Chem; 24(6):1180-1186.

\section{ARABIC SUMMARY}

\section{Rhynchophorus ferruginous بعض الأملاح غير العضوية كمعقمات ضد سوسة النخيل الحمرا}

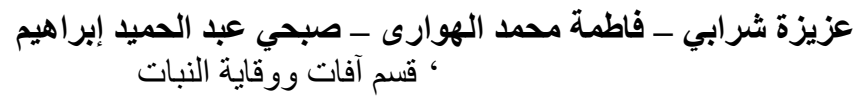

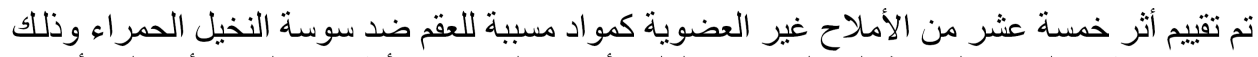

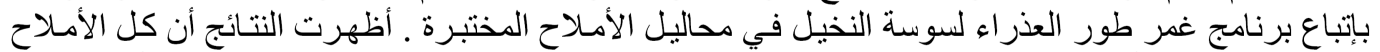

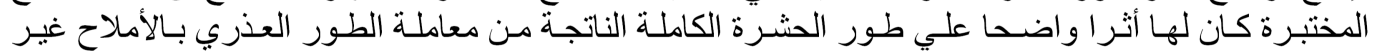

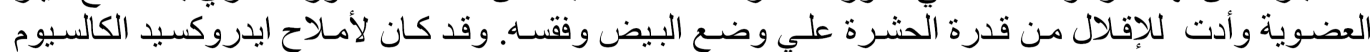

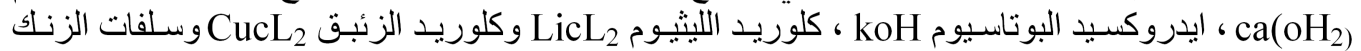

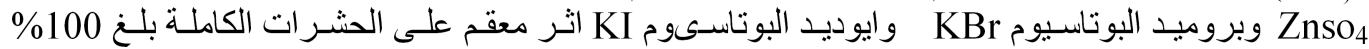

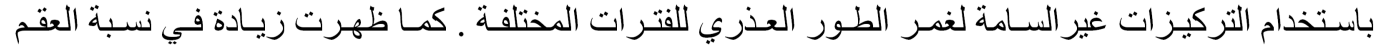

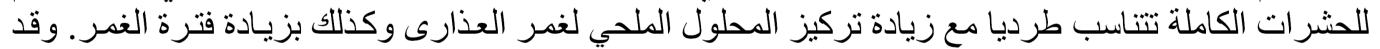

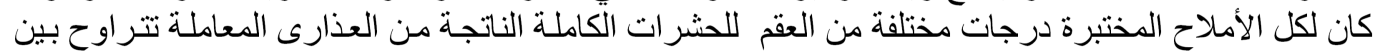

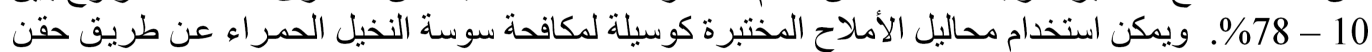

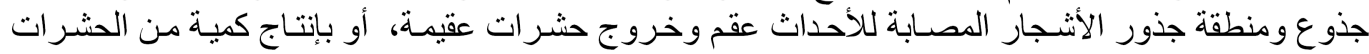

